\title{
Moderating Role of Acculturation and School Type on Association between Parenting Style and Positive Psychological Development among Iranian Adolescents in Malaysia
}

\author{
Shahnaz Sheibani ${ }^{1}$, Rumaya Juhari ${ }^{1} \&$ Majid Yoosefi Looyeh ${ }^{2}$ \\ ${ }^{1}$ Faculty of Human Ecology, University Putra Malaysia, Malaysia \\ ${ }^{2}$ Faculty of Psychology and Social Science, Islamic Azad University, Central Tehran Branch, Iran \\ Corresponding author: Rumaya Juhari, Faculty of Human Ecology, University Putra Malaysia, 43400, Serdang, \\ Selangor Darul Ehsan, Malaysia
}

Received: November 24, 2019

Accepted: January 28, 2020

Online Published: February 26, 2020

doi:10.5539/ijps.v12n1p32

URL: https://doi.org/10.5539/ijps.v12n1p32

\begin{abstract}
This study examines the moderating role of acculturation and school type (Iranian vs. International schools) on the association between parenting style and positive psychological development (PPD) among Iranian youth in Malaysia. Some 194 Iranian adolescents were selected from Iranian and International schools using the stratified random sampling method. The Iranian Version of the Self-Identity Acculturation Scale (SL-ASIA), Alabama Parenting Questionnaire (APQ), and Positive Youth Development-Short Form (PYD-SF) were employed. Partial Least Squares Structural Equation Modelling (PLS-SEM) was used for data analysis. The results indicated that acculturation moderated the association between father involvement and poor monitoring in the PPD of adolescents. Moreover, positive parenting moderated the correlation between the total scores for acculturation and PPD, although the school type did not. The current study has indicated the importance of the role of acculturation on the association between parenting and PPD of migrated Iranian adolescents in host countries.
\end{abstract}

Keywords: acculturation, Iranian adolescents, parenting, positive psychological development, school type

\section{Introduction}

The current article contains an introduction to the study, a brief statement of the problem, the method of study, the results, discussion and conclusion.

Adolescence is a transitional stage that is considered to be a bridge between childhood and adulthood. According to Erikson, the social and cultural variables are one of the most critical factors that affect the positive well-being of adolescents. As a result, changing the social environment such as migration to another culture is a crucial trigger for adolescence crisis. On the other hand, the phenomenon of migration (either temporary or permanent) to other countries is one of the critical issues affecting many developing countries. According to the United Nations (2019), there are 37.85 million international immigrants under the age of 19, which represents 13.9 percent of all international immigrants. Many international immigrants under the age of 20 belong to Asian countries such as Iran.

This migration causes adolescents to face many challenges with regard to their positive psychological development (PPD). These challenges affect their lives to a great degree. Hence, it is worthwhile to study the positive well-being of Iranian adolescents in order to develop the necessary social and emotional competencies for a better transition to adulthood (Jafari, Baharlou, \& Mathias, 2010).

Furthermore, in the case of migration, investigating the role of acculturation has become one of the central issues as reflected by a literature review concerning the adaptive process of immigrant adolescents (Hamilton et al., 2012; Kennedy and MacNeela, 2014). The adaptive process may be particularly tricky because it is related to many variables including beliefs, behaviours, attitudes, values and the ethnic identity of the individual (Motti-Stefanidi et al., 2008). According to Berry et al. (2008), more studies should be undertaken to further clarify the effects of acculturation on the PPD of migrated adolescents.

It is crucial to include the family status of the immigrants and their circumstances in order to examine the consequences that these factors may have on the family. The family is responsible for fostering children, as well 
as to develop the next generation. However, the needs of the children in immigrant families are different from those in the non-immigrant cases. Some vital factors that have been identified to be associated with the immigrant families are the socio-cultural status of the family including the parents' relationship with the adolescents, the income of the parents, and the family social and educational status (Bhalla \& McCormick, 2009; Gatina, 2016; Hernandez et al., 2007; Javier et al., 2015; Johnston et al., 2013). A substantial aspect of contextual factors, which are a critical issue for adolescents, is the educational environment including their school (Kroening \& Dawson-Hahn, 2019). Previous studies have recognised that the school circumstances have positive and negative psychological effects on immigrant adolescents. The research findings in this issue were paradoxical (Lin et al., 2011; Hamilton et al., 2012).

Generally, in the context of migration, one of the most crucial issues for immigrant families is the outcomes of the studies concerning the influence of migration on the psychological development of their children and adolescents, and the next generation. Previous studies have shown paradoxical psychological consequences of migration for these families and the next generation (Akbulut-Yuksela \& Kuglerb, 2016; Chadwick \& Collins, 2015; Greenea \& Maggsb, 2018). Berry et al. (2008) showed that low positive psychological development affects immigrant adolescents, as well as their families. For instance, some studies indicated that Iranian immigrant adolescents in the United States had poor psychological development that was related to poor language proficiency, discrimination, homesickness, and poor social adaptation (Ghanbari, 2013). However, in other societies such as the United States, Spain, and Italy, the immigrant adolescents have shown unexpected higher levels of positive psychological development (Lara, 2014; Bobowik, Basabe and Páez, 2015; Akbulut-Yuksel and Kugler, 2016). According to Joppke (2010), it is the obligation of the host countries to protect and work towards the interests of the immigrants as the latter do have a right as a minority and contribute towards the economy of the country. Therefore, it is important to consider how well the immigrants are doing in countries where a majority of immigration takes place. Unfortunately, most of studies in this area are conducted only in the Western societies.

It is only recently that a few articles have investigated the relationship between psychological problems and the family and personal factors of Iranian immigrant youths in Malaysia (Rabbani, M; Mansor, M B; Yaacob, S N; Talib, 2014; Mobarakeh et al., 2015). Arbabi et al. (2017) found that the migration of Iranian adolescents is a period of unpredicted encounters that most likely immigrant youths in other societies may not experience. This migration could be related to initial high expectations, diversities in culture, beliefs, and views, social problems, and variances in individual appraisals along with other psychological difficulties. Regarding the definitions of strategies of acculturation including assimilation, separation, integration and marginalisation, primary personal observation illustrates that Iranian people in Malaysia attempt to preserve some aspect of their culture of origin such as celebrating the Nowruz (Iranian New Year), Cheleh Night (The longest night in the year), Wednesday Fireworks (as the last Wednesday in the year), and their national Fathers' as well Mother' days. Also, some Iranians in Malaysia celebrate the new cultural events that are related to recent decades after the Islamic revolution. In other words, Iranian people in Malaysia have their own communities and do not simply adopt the dominant norms in Malaysian groups or Malaysian culture as the host country. Therefore, future studies could focus on investigating the exact state strategies of acculturation and its explanation among Iranians in Malaysia and compare their strategies of acculturation in other Eastern and even Western countries. Shafaei et al. (2016)explored the acculturative strategies adopted by 1186 international students in Malaysia and reported that the dominant strategy was integration. Predictors such as proficiency in English, usage of media, intention to remain in Malaysia after completion of studies, and a positive stereotype image were found to be significantly related with integration strategy. At the same time, demographic variables had no effect on the choice of strategy.

Additionally, the present study is crucial for the theoretical expansion, design of relevant and customised intervention programmes for the families and the adolescents, and for policy development. In addition, this research builds upon the findings from previous studies by investigating the interaction between the family, and contextual factors related to the positive well-being of Iranian adolescents. Concerning the theoretical expansion, the findings of the current study will extend the Positive Youth Developmental Theory (Lerner et al., 2002) by demonstrating the integrative relations that exist between adolescents and their multilevel context including family factors such as parenting, as well environmental factors including acculturation and school type.

For the design of customised intervention programmes, the conclusions of this study can be useful for school psychologists and counsellors who work with immigrant youths and their parents to prevent psychological problems. The conclusions also promote positive development that focuses on competence, confidence, character building, connections, and caring relationships. 
The present study aims to explore the moderating role of acculturation and school type on the relationship between parenting and the PPD of Iranian adolescents in Malaysia. The study also attempts to extend the existing knowledge in the context of the psychological outcomes among Asian immigrant adolescents.

\section{Method}

A total of 194 Iranian adolescents (girls $n=84$ and boys $n=112$, aged 11 to 15 years old) participated from two types of Iranian and International schools in Selangor, Malaysia $(\mathrm{M}=13.50, \mathrm{SD}=1.68)$. The sampling method chosen was stratified random sampling. After gathering the consent letters, the data collection was completed in two sessions. The respondents were asked to answer the demographic questionnaire and the Alabama Parenting Questionnaire (APQ) (Frick, 1991). The APQ measures five dimensions of parenting style which include positive involvement with children, supervision, monitoring, the use of positive discipline techniques, consistency in the use of parental discipline, and the use of corporal punishment. The Cronbach's Alpha of the APQ subscales was found to be in the range 0.69 to 0.95 which was considered to be a high degree of reliability. Then, to assess acculturation, the respondents were asked to answer a modified Iranian version of the Suinn-Lew Asian Self-Identity questionnaire (SL-ASIA) (Suinn et al., 1987; Khanideh, 2007). The internal validity for the SL-ASIA (Cronbach's Alpha) was 0.87 . To assess the positive psychological development, the Positive Youth Development-Short Form (PYD-SF) was used. The PYD-SF was a self-report measure, which assesses competence, confidence, character, caring, and connection (Geldhof et al., 2014). The Cronbach's Alpha for PYD-SF was .86 which is a high reliability value.

Prior to the actual data collection, a pilot study was conducted in order to (a) determine the comprehension of the questionnaires and to modify any unclear items; (b) determine the reliability of the questionnaires; (c) to determine the approximate time required to fill out the questionnaires. A small group $(n=40)$ of adolescents participated in the pilot study who were selected by convenience sampling and included Iranian adolescents from Marefat Iranian School $(n=20)$ and Syfol International School $(n=20)$. The adolescents who participated in the pilot study were not included in the main study sample. To assess the reliability of the questionnaires, the Cronbach's Alpha was employed.

\section{Results}

Exploratory data analysis (EDA) was used as a fundamental step in the research analysis. The main purpose of EDA is to examine the data for distribution, detecting missing data, outliers, and normality to direct exact testing of the research hypotheses (Komorowski et al., 2016). In the present study, there were $3.5 \%$ missing data per indicator. According to Hair Jr et al. (2016), when there are less than $5 \%$ values missing per indicator, then the Mean value replacement method can be used. Also, in the current study, there were no outliers with respect to the Mahalanobis distance.

PLS-SEM was used for data analysis in the present study. As PLS-SEM is a nonparametric statistical method, verifying the normality distribution of the data is important. In the present study, the distribution of data was normal since the skewness values were from -1.884 to 2.00 and the kurtosis values were from - .0192 to 3.818 for all variables. According to George (2011), in order to validate the normality of a data distribution, the value of the skewness value should be between -2 to +2 and the value of the kurtosis must be between -7 to +7 . Based on PLS-SEM, the existing high correlations (more than 0.90) between more than two indicators is referred to as multicollinearity and shows a methodological problem that represents the same underlying construct (Pallant, 2010; Byrne, 2013). In the current study, the correlation values between the variables were below 0.90. This indicates that there was no multicollinearity among the study variables. According to Pallant (2010), multicollinearity can be determined by the Tolerance value and the Variance Inflation Factor (VIF). The Tolerance value indicates the extent to which the variability of the specified independent variable is not explained by the other independent variables in the model. A Tolerance value of less than 0.1 shows high multiple correlations with other independent variables which indicates the possibility of multicollinearity. In contrast to the Tolerance value, if the value of VIF is more than 10, it shows multicollinearity. In the current study, all values of Tolerance were more than 0.1 and all values of VIF were less than 10 . Therefore, all prerequisite requirements for using PLS-SEM were considered and satisfied.

The collected data was analysed in two different parts. In the first part, a descriptive analysis was used to report the statistical indicators including frequency, percentages, Mean, standard deviation, reliability, and validity of the samples. For the descriptive analysis, the IBM Statistical Package for the Social Sciences (SPSS) version 21 was employed. In the second part, inferential statistics were used for analysing the data. In the inferential analysis, Structural Equation Modelling (SEM) was employed by using Partial Least Squares Structural Equation Modelling (PLS-SEM), and Smart PLS 2.0 software to test the structural model for the moderating effect of the 
independent variables (Hair Jr et al., 2016). This was done because SEM is based on the principles employed in regression analysis. Therefore, SEM provided coefficients to inform how much Y would change if X increased and measured how well the model fitted the data (Chadwick and Collins, 2015).

The study respondents consisted of Iranian adolescents living in Kuala Lumpur who were going to Iranian or International schools. Some $57 \%$ of the respondents were boys and $42 \%$ were girls. Additionally, $58 \%$ of the respondents were in Iranian schools and $41 \%$ of respondents were in International schools. The age range of the respondents was between 11 to 15 years old $(\mathrm{Mean}=13.36, \mathrm{SD}=1.54)$. In terms of duration of residency, $70.02 \%$ of the respondents had been resident in Malaysia for more than three years, $16.49 \%$ of them had lived less than one year in Malaysia, while $12.89 \%$ of the respondents had lived between 1 to 3 years in Malaysia. It was notable that all adolescents who had residency of less than three years in Malaysia were studying in Iranian schools. The maximum Mean score of the positive psychological development of the adolescents was related to those adolescents who were 11 years old $(M e a n=126.3, \mathrm{SD}=13.37)$ and the minimum Mean was related to the adolescents who were 13 years old (Mean=113.4, $\mathrm{SD}=22$ ).

In order to investigate the moderating role of acculturation and type of school on the association between parenting and the positive psychological development of the adolescents, multigroup analysis was employed. The multigroup analysis provided the possibility of testing for differences between identical models estimated for different groups of respondents (Hair Jr et al., 2016). In this method, the respondents were divided into two or more groups according to the scores of the moderator variables. If the difference between the results of these two groups was significant, it meant that the moderator variable had a significant moderating effect on the relationship between independent variable (IV) and the dependent variable (DV).

For testing the moderating roles of acculturation between the exogenous variable, parenting, and the endogenous variable, the positive psychological development of the adolescents and multi-group model analysis were performed and the data was divided into high and low groups (Table 1).

Table 1. Result of multiple group analysis of moderating effect of acculturation on parenting style and adolescents' positive psychological development (PPD) of the adolescents

\begin{tabular}{cccccc}
\hline Path & $\begin{array}{c}\text { Low group } \\
\text { Beta. }\end{array}$ & $\begin{array}{c}\text { High group } \\
\text { Beta. }\end{array}$ & L-H & T value & $P$ \\
& -0.13 & -0.05 & 0.08 & 1.04 & 0.301 \\
\hline Corporal Punishment-> PPD & $3.49^{*}$ & 0.97 & & & \\
& 0.43 & 0.17 & -0.26 & 3.99 & $0.001^{*}$ \\
Father involvement-> PPD & $6.02^{*}$ & $5.12^{*}$ & & & \\
& -0.04 & -0.01 & 0.03 & 0.75 & 0.454 \\
Inconsistent Discipline-> PPD & 1.39 & 0.22 & & & \\
Mother Involvement-> PPD & 0.04 & 0.14 & 0.1 & 1.09 & 0.279 \\
& 0.70 & $2.24^{*}$ & & & \\
Poor Monitoring ->PPD & -0.70 & -0.13 & 0.57 & 9.98 & $0.001^{*}$ \\
& $9.54^{*}$ & $5.50^{*}$ & & & \\
Positive Parenting-> PPD & 0.28 & 0.39 & 0.10 & 1.51 & 0.134 \\
& $7.75^{*}$ & $6.90^{*}$ & & & \\
\hline
\end{tabular}

$* \mathrm{~T}$ Value $>1.96$, Significance at $0.05 ; \mathrm{T}$ value $>2,57$, Significance at $0.01 ; \mathrm{T}$ Value $>3.26$, Significance at 0.001 .

As indicated in Table 1, the results indicated that acculturation did not moderate the association between PPD and corporal punishment $(\mathrm{T}=1.04, \mathrm{p}<0.301)$, inconsistent discipline $(\mathrm{T}=0.75, \mathrm{p}<0.454)$, mother's involvement $(\mathrm{T}=1.09, \mathrm{p}<0.279)$, and positive parenting $(\mathrm{T}=1.51, \mathrm{p}<0.134)$. On the other hand, acculturation did significantly moderate the association between the adolescent PPD with father's involvement $(T=3.99, \mathrm{p}<0.001)$ and poor monitoring $(\mathrm{T}=9.98, \mathrm{p}<0.001)$. Based on an exhaustive search of online published article databases such as Science Direct, PubMed, Scopus, Springer Link, and Taylor and Francis, only a few recent articles are available which have investigated the moderating role of acculturation on relationships between some personal 
factors. Berry (2006) stressed that the immigrant status of the adolescents does impact their well-being. Luk et al. (2013) reported that acculturation moderated the association between religiosity and substance use outcomes among Asian Americans. Jamal and Shukor (2014) indicated that acculturation moderates the effects of self-congruity and susceptibility to interpersonal influence. Ethnic identity, acculturation, and PPD were positively correlated to each other according to (Balidemaj, 2016). Schwartz et al. (2016) also stated how the response of the parents to acculturation can impact the positive development of the adolescents. Higher levels of parenting-specific psychological flexibility were found to be indirectly related to lower levels of youth internalising and externalising problems through adaptive parenting practices (Brassell et al., 2016). Therefore, the lack of parental flexibility to adapt to circumstances can affect the approach of the adolescents to acculturation, and hence, their PPD. The structural model that is given in Figure 1 is used to evaluate the moderating roles of the High group of acculturation on the relationship between parenting style and adolescent PPD. The structural model that is shown in Figure 2 presents the moderating roles of the Low group of acculturation on the relationship between parenting style and adolescent PPD.

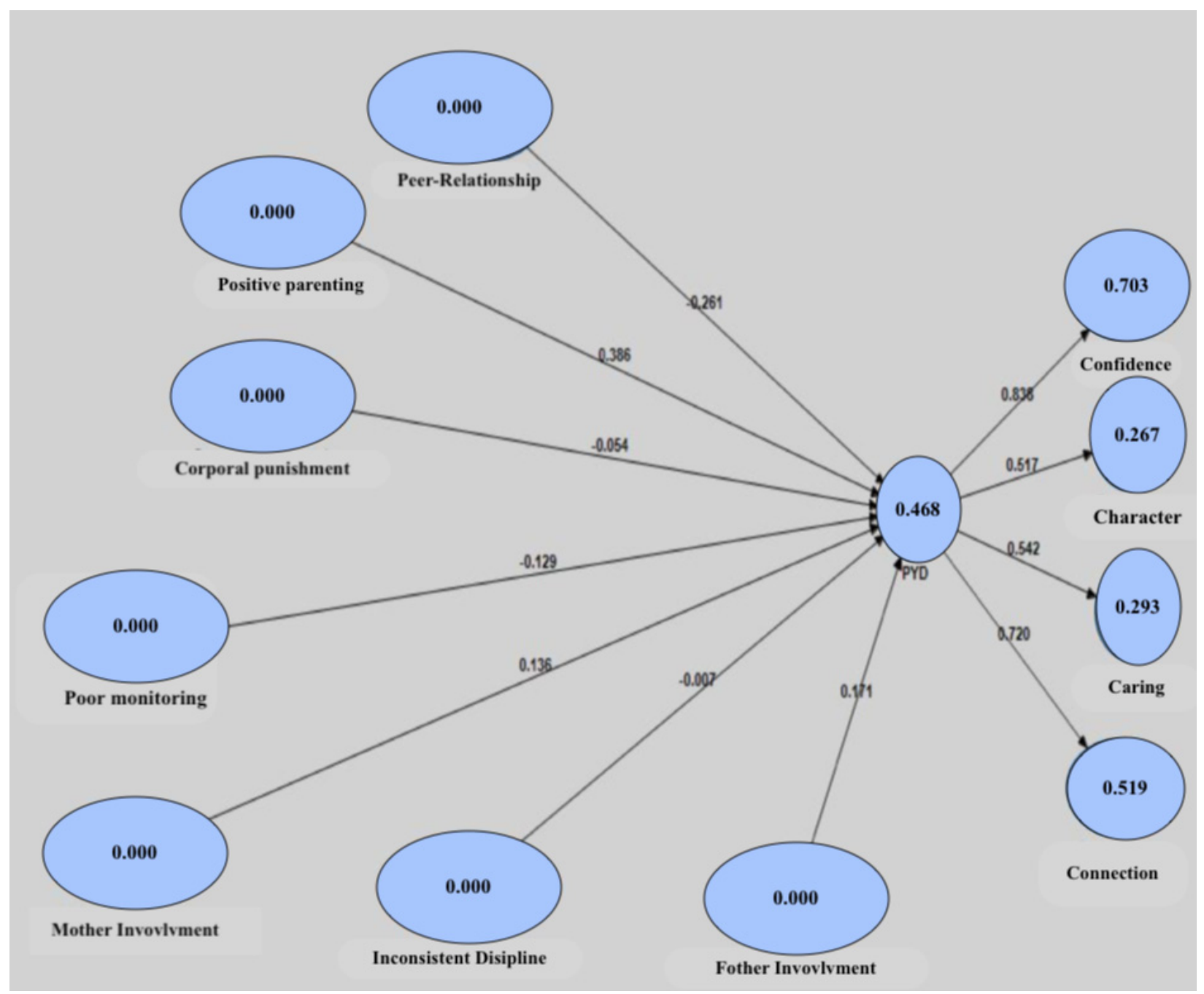

Figure 1. The moderating effect of High Acculturation between IV and DV 


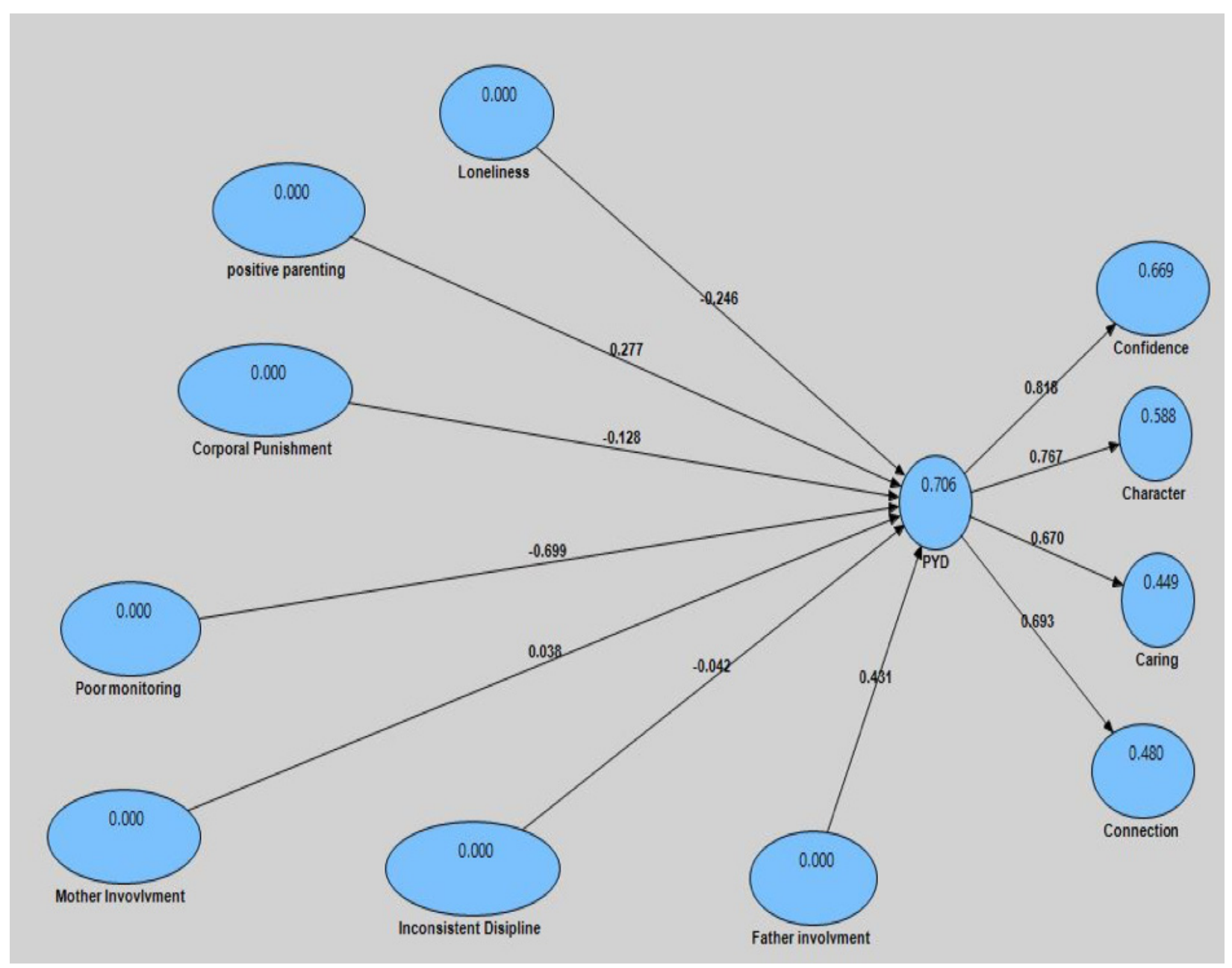

Figure 2. The moderating effect of Low Acculturation between IV and DV

For testing the moderating role of the type of school between parenting style as the exogenous variable and the adolescent PPD as the endogenous variable, then multigroup model analysis was performed, and the data was divided into categories of International and Iranian schools (Table 2). 
Table 2. sults of multiple group analysis of moderating effect of school type (Iranian vs International) on parenting style and adolescents' positive psychological development (PPD) of the adolescents

\begin{tabular}{cccccc}
\hline Path & $\begin{array}{c}\text { International } \\
\text { School } \\
\text { Beta. }\end{array}$ & $\begin{array}{c}\text { Iranian } \\
\text { School }\end{array}$ & IN-IR & $T$ & $P$ \\
& Beta. & & value & Value \\
\hline Corporal Punishment-> PPD & -0.43 & 0.01 & 0.44 & 1.47 & 0.071 \\
& $4.60^{*}$ & 0.10 & & & \\
Father involvement-> PPD & 0.33 & 0.30 & -0.03 & 0.38 & 0.708 \\
& $4.17^{*}$ & $3.71^{*}$ & & & \\
Inconsistent Discipline-> PPD & 0.38 & 0.04 & -0.34 & 1.17 & 0.13 \\
& $2.17^{*}$ & 0.62 & & & \\
Mother Involvement-> PPD & 0.49 & 0.30 & -0.19 & 1.24 & 0.216 \\
& $4.84^{*}$ & $2.82^{*}$ & & & \\
Poor Monitoring ->PPD & 0.06 & -0.34 & -0.4 & 1.61 & 0.061 \\
Positive Parenting-> PPD & 0.13 & $7.38^{*}$ & & & \\
& 0.12 & 0.14 & 0.02 & 0.23 & 0.784 \\
& 1.04 & $3.42^{*}$ & & & \\
\hline
\end{tabular}

*T Value $>1.96$, Significance at 0.05

As is evident from Table 2, none of the relationships between the variables were found significant as the $p$ values were not less than 0.05 in any case. The results showed that the moderating role of the school type (Iranian vs. International) between all subscales of parenting style and adolescent PPD was not significant. However, prior studies have indicated that the type of school moderates the relationship between other contextual factors and PPD. For instance, research has shown that the school type (public vs migrant schools) moderated stigma and perceived discrimination and levels of personal and collective self-esteem as well as life satisfaction in migrant adolescents (Liu and Zhao, 2016; Jia and Liu, 2017). The difference in the findings of the present study and prior studies may relate to different IV and the population of the study. There is, however, no way to confirm this finding as a review of the literature did not reveal any earlier study which has explored this moderating role of the school type in parenting and adolescent PPD.

\section{Discussion}

The current study examined the moderating role of acculturation and the school type on the relationship between parenting style and adolescent PPD among Iranian adolescents in Malaysia. It was found that acculturation did not moderate the association between the PPD of the adolescents and the parenting style. The quality of parenting was measured by the factors of corporal punishment, inconsistent discipline, mother's involvement, and positive parenting which were found to not be related. However, acculturation did moderate the association between father's involvement and poor monitoring with adolescent PPD. Moreover, positive parenting moderated the correlation between the total scores for acculturation and PPD. This relationship was also corroborated by other studies (Luk et al., 2013; Lara, 2014; Jang, 2016).

Likewise, the results of the present study did not find that the school type and the quality of parenting contributed to the PPD of the adolescents. A study of 139 Albanian-American immigrants aged 21 to 35 showed that acculturation and PPD were related with graduate school education playing a part in the relationship (Balidemaj, 2016). This variable has not been explored by many studies with respect to the school type. However, parenting style and the PPD of adolescents have been linked by many studies (Khan, Taghdisi and Nourijelyani, 2015; Stafford et al., 2016).

As a result, most factors of the quality of parenting were not found to moderate the relation to PPD. However, when acculturation was checked for a direct relationship with the adolescent PPD, a significant and positive relationship was found with moderate strength. A study of 588 adolescent immigrants, 11 to 20 years old, from the Soviet Union, Turkey, Somalia, and Vietnam, living in Finland, revealed that PPD was affected by acculturative stress for all adolescents (Liebkind and Jasinskaja-Lahti, 2000). Another study, using the 1997 to 
1998 WHO study on school children for adolescents from four racially diverse countries who were immigrants in the US, also found a link between acculturation and PPD (Yu et al., 2003). Therefore, despite the findings of the current study, this relationship does require further research to understand the role played by acculturation in this context. For this study, it is evident that the quality of parenting and also acculturation do indeed influence the PPD of the adolescents but do not interact or influence each other very much.

\section{Conclusion}

Regarding the results of the current study, there is a need to study acculturation, states of depression or well-being, and performance (academic and in other spheres of life such as hobbies, sports, socialisation) for Iranian adolescents living in Malaysia. Such studies would allow a deeper and richer understanding of the mental and emotional state of Iranian adolescents living in a host country. Moreover, future researchers should focus on ascertaining whether there is a difference between the PPD for men and women and boys and girls. In other words, the moderating role played by age while ascertaining the relationship between gender and PPD should be explored. Likewise, similar studies for Iranian adolescents settled in other countries are also needed to understand the role played by the Malaysian context in this study. This is necessary to understand if the acculturation issues and parental factors are applied differently in the Malaysian context from other countries.

There were limitations associated with the present study. The findings of the current study cannot be generalised to Iranian adolescents in other countries. Similarly, the PPD has an association with a wide range of individual, family, and contextual factors. The present study focused on only a few of these factors.

\section{References}

Akbulut-Yuksel, M. \& Kugler, A. D. (2016). Intergenerational persistence of health: Do immigrants get healthier as they remain in the US for more generations? Economics and Human Biology, 23, 136-148. https://doi.org/10.1016/j.ehb.2016.08.004.

Alaeikharaem, R. (2013). Casual model of family, environmental, and personal factors on substance use among adolescents in Karaj country. Country Development, 2, 141-161.

Arbabi, K. (2017). From Monocultural to Multicultural: Adaptation of Iranian Immigrant Adolescents in Malaysia. Journal of Adolescent Research, 32(3), 371-402. https://doi.org/10.1177/0743558416630811.

Balidemaj, A. (2016). Acculturation, Ethnic Identity, and Psychological Well-being of Albanian-American Immigrants in the United States, 20th International Conference on Rights of Refugees and Migration Law. Available at: http://tigerprints.clemson.edu/all_dissertations.

Bhalla, A. S. \& P. McCormick (2009). Poverty among immigrant children in. New Yourk: Palgrave Macmillan.

Berry, J. W. (2006). Acculturative stress, in Handbook of multicultural perspectives on stress and coping. Springer, 287-298.

Berry, J. W. (2008). Response to Rudmins Book: Review of Immigrant Youth in Cultural Transition. Journal of Cross-Cultural Psychology, 39, 517-520. https://doi.org/10.1177/0022022108318135.

Bobowik, M., Basabe, N. \& Páez, D. (2015). The bright side of migration: Hedonic, psychological, and social well-being in immigrants in Spain. Social Science Research, 51, 189-204. https://doi.org/10.1016/j.ssresearch.2014.09.011.

Brassell, A. A. (2016). Parents psychological flexibility: Associations with parenting and child psychosocial well-being. Journal of Contextual Behavioral Science, 5(2), 111-120. https://doi.org/10.1016/j.jcbs.2016.03.001.

Byrne, B. M. (2013). Structural equation modeling with Mplus: Basic concepts, applications, and programming. Routledge.

Chadwick, K. A. \& Collins, P. A. (2015). Examining the relationship between social support availability, urban center size, and self-perceived mental health of recent immigrants to Canada. Social Science and Medicine, 128, 220-230. http://dx.doi.org/10.1016/j.socscimed.2015.01.036.

Erikson, E. (1963). Youth: Change and challenge, Retrieved February, 1-7. Available at: $\mathrm{http} / /$ scholar.google.com/scholar?hl=en\&btnG=Search\&q=intitle:The+Developmental+Stages + of + Erik + Er ikson\#3\%5Cnhttp://scholar.google.com/scholar?hl=en\&btnG=Search\&q=intitle:The+developmental+stages + of + Erik+Erikson\% 233 .

Frick, P. (1991). The Alabama Parenting Questionnaire. Unpublished rating scale, University of Alabama, 223-. https://doi.org/10.1007/s10826-006-9082-5. 
Gatina, L. (2016). Does money buy happiness? Financial and general well-being of immigrants in Australia. Journal of Behavioral and Experimental Economics, 63, 91-105. https://doi.org/10.1016/j.socec.2016.04.018.

George, D. (2011). SPSS for windows step by step: A simple study guide and reference, 17.0 update, 10/e. Pearson Education India.

Ghanbari, A. (2013). Pathology of Iranian presence in Malaysia. Available at: http://www.kualalumpur.icro.ir/index.aspx?siteid=262\&pageid=31329 (Accessed: 15 June 2017).

Greenea, K. M. \& Maggsb, J. L. (2018). Immigrant paradox? Generational status, alcohol use, and negative $\begin{array}{lllll}\text { consequences across college. Addictive Behaviors, } & \text { 87, }\end{array}$ https://doi.org/10.1016/j.addbeh.2018.06.030

Geldhof, G. J. (2014). The creation and validation of short and very short measures of the five Cs of positive youth development. Journal of Research on Adolescence, 24(1), 163-176. https://doi.org/10.1111/jora.12039.

Hair Jr, J. F. (2016). A primer on partial least squares structural equation modeling (PLS-SEM). Sage publications.

Hamilton, H. A. (2012). The roles of family, peer, school, and attitudinal factors in cannabis use across immigrant generations of youth. Journal of Drug Issues, 42(1), 46-58. https://doi.org/10.1177/0022042612436652.

Hernandez, D. J., Denton, N. A. \& Macartney, S. E. (2007). Family circumstances of children in immigrant families: Looking to the future of America., in Lansford, J E; Deater-Deckard, K; Bornstein, M. H. (ed.) Immigrant families in contemporary society. 9-29. Available at: http://ezproxy.lib.cam.ac.uk:2048/login?url=http://search.ebscohost.com/login.aspx?direct=true\&db=psyh\& AN=2007-11856-001\&site $=$ ehost-live\&scope $=$ site.

Javier, J. R., Festa, N. \& Mendoza, F. S. (2015). Children in immigrant families: The foundation for Americas uture. Advances in Pediatrics, 62, 105-136. https://doi.org/10.1016/j.yapd.2015.04.013

Jamal, A. \& Shukor, S. A. (2014). Antecedents and outcomes of interpersonal influences and the role of acculturation: The case of young British-Muslims. Journal of Business Research, 67(3), 237-245. https://doi.org/10.1016/j.jbusres.2013.05.009.

Jang, S. H. (2016). First-generation Korean immigrants barriers to healthcare and their coping strategies in the US. Social Science and Medicine, 168, 93-100. https://doi.org/10.1016/j.socscimed.2016.09.007.

Jia, X. \& Liu, X. (2017). Perceived discrimination and antisocial behaviour among Chinese rural-to-urban migrant adolescents: Mediating effects of social support. International Journal of Psychology. https://doi.org/10.1002/ijop.12280.

Johnston, J., Harwood, C. \& Minniti, A. M. (2013). Positive youth development in swimming: Clarification and consensus of key psychosocial assets. Journal of Applied Sport Psychology, 25, 392-411. https://doi.org/10.1080/10413200.2012.747571

Joppke, C. (2010). Minority Rights for Immigrants? Multiculturalism versus Antidiscrimination. Israel Law Review, 43(1), 49-66. https://doi.org/10.1017/S0021223700000042.

Kennedy, L. A. \& MacNeela, P. (2014). Adolescent acculturation experiences: A meta-ethnography of qualitative research. International Journal of Intercultural Relations, 40, 126-140. https://doi.org/10.1016/j.ijintrel.2013.11.003.

Khan, Y., Taghdisi, M. H. \& Nourijelyani, K. (2015). Psychological Well-Being (PWB) of School Adolescents Aged 12-18 yr, its Correlation with General Levels of Physical Activity (PA) and Socio-Demographic Factors In Gilgit, Pakistan. Iranian Journal of Public Health, 44(6), 804-813.

Khanideh, S. (2007). Attitudes of female Iranian immigrants toward seeking psychological help as a function of acculturation. Massachusetts: School of Professional Psychology.

Komorowski, M. (2016). Exploratory Data Analysis, in Secondary Analysis of Electronic Health Records. Springer, 185-203.

Kroening, A. L. H. \& Dawson-Hahn, E. (2019). Health considerations for immigrant and refugee children. Advances in Pediatrics, 66, 87-110. https://doi.org/10.1016/j.yapd.2019.04.003 
Lara, L. (2014). Psychological Well-being of Immigrants in Spain: The Immigrant Paradox. Procedia - Social and Behavioral Sciences, 132, 544-548. https://doi.org/10.1016/j.sbspro.2014.04.351.

Lerner, R. M., Rothbaum, F., Boulos, S. \& Castellino, D. R. (2002). Developmental system theory. In M. H. Bornstein (Ed.), Handbook of parenting: Biology and ecology of parenting (Vol. 2). Lawrence Erlbaum Associates, Inc.

Liebkind, K. and Jasinskaja-Lahti, I. (2000). Acculturation and psychological well-being among immigrant adolescents in Finland: A comparative study of adolescents from different cultural backgrounds. Journal of Adolescent Research. Sage Publications Sage CA: Thousand Oaks, CA, 15(4), 446-469.

Lin, F. G. (2011). Interactive influences of family and school ecologies on the depression status among children in marital immigrant families. Research in Developmental Disabilities, 32(6), 2027-2035. https://doi.org/10.1016/j.ridd.2011.08.009.

Liu, X. \& Zhao, J. (2016). Chinese migrant adolescents perceived discrimination and psychological well-being: The moderating roles of group identity and the type of school. PloS one, Public Library of Science, 11(1), p. e0146559. https://doi.org/10.1371/journal.pone.0146559

Luk, J. W. (2013). Religiosity and substance use among Asian American college students: Moderated effects of race and acculturation. Drug and Alcohol Dependence, 130(1-3), 142-149. https://doi.org/10.1016/j.drugalcdep.2012.10.023.

Mobarakeh, M. R. V (2015). The Effects of Personality Traits and Psychological Well-Being among Iranian Adolescent Migrants in Kuala-Lumpur, Malaysia. IOSR Journal Of Humanities And Social Science, 20(7), 25-28. https://doi.org/10.9790/0837-20712528.

Motti-Stefanidi, F. (2008). Acculturation and adaptation of immigrant adolescents in Greek urban schools. International Journal of Psychology, 43(1), 45-58. https://doi.org/10.1080/00207590701804412.

Pallant, J. (2010). A step by step guide to data analysis using SPSS, Berkshire UK: McGraw-Hill Education. Open University Press Milton Keyne.

Rabbani, M; Mansor, M B; Yaacob, S N. \& Talib, M. A. (2014). The relationship between social support, coping strategies, and stress among Iranian adolescents living in Malaysia. The Online Journal of Counseling and Education, 3, 52-63.

Schwartz, S. J. (2016). Testing the parent-adolescent acculturation discrepancy hypothesis: A five-wave longitudinal study. Journal of Research on Adolescence. Wiley Online Library, 26(3), 567-586.

Stafford, M. (2016). Parent-child relationships and offsprings positive mental wellbeing from adolescence to early older age. Journal of Positive Psychology, 11(3). https://doi.org/10.1080/17439760.2015.1081971.

Suinn, R. M. (1987). The Suinn-Lew asian self-identity acculturation scale: An initial report. Educational and Psychological Measurement, 47(2), 401-407. https://doi.org/10.1177/0013164487472012.

United Nations (2019). International migrant stock 2019.

$\mathrm{Yu}, \mathrm{S} . \mathrm{M}$. (2003). Acculturation and the health and well-being of US immigrant adolescents. Journal of Adolescent Health, 33(6), 479-488. https://doi.org/10.1016/S1054-139X(03)00210-6.

\section{Copyrights}

Copyright for this article is retained by the author(s), with first publication rights granted to the journal.

This is an open-access article distributed under the terms and conditions of the Creative Commons Attribution license (http://creativecommons.org/licenses/by/4.0/). 